\title{
Apoptosis caused by cathepsins does not require Bid signaling in an in vivo model of progressive myoclonus epilepsy (EPM1)
}

\author{
MK Houseweart ${ }^{1}$, A Vilaythong ${ }^{2}$, X-M Yin ${ }^{3}$, B Turk ${ }^{4}$, JL Noebels ${ }^{2}$ \\ and RM Myers*,1 \\ 1 Department of Genetics, School of Medicine, Stanford University, 300 Pasteur \\ Drive, Stanford, CA 94305-5120, USA \\ 2 Department of Neurology and Molecular and Human Genetics, Baylor College \\ of Medicine, Houston, TX 77030, USA \\ 3 Department of Pathology, University of Pittsburgh, Pittsburgh, PA 15261, USA \\ ${ }^{4}$ Department of Biochemistry and Molecular Biology, J. Stefan Institute, \\ Ljubliana, Slovenia \\ * Corresponding author: RM Myers. Tel: + 1-650-725-9687; \\ Fax: + 1-650-725-9689; E-mail: myers@ @shgc.stanford.edu
}

Received 08.12.02; revised 05.6.03; accepted 27.6.03; published online 8 August 2003

Edited by Dr G Salvesen

\section{Abstract}

Apoptosis can be mediated by mechanisms other than the traditional caspase-mediated cleavage cascade. There is growing recognition that alternative proteolytic enzymes such as the lysosomal cathepsin proteases can initiate or propagate proapoptotic signals, but it is currently unclear how cathepsins achieve these actions. Recent in vitro evidence suggests that cathepsins cleave the proapoptotic Bcl-2 family member Bid, thereby activating it and allowing it to induce the mitochondrial release of cytochrome $c$ and subsequent apoptosis. We have tested this hypothesis in vivo by breeding mice that lack cathepsin inhibition (cystatin B-deficient mice) to Bid-deficient mice, to determine whether the apoptosis caused by cathepsins is dependent on Bid signaling. We found that cathepsins are still able to promote apoptosis even in the absence of Bid, indicating that these proteases mediate apoptosis via a different pathway, or that some other molecule can functionally substitute for Bid in this system.

Cell Death and Differentiation (2003) 10, 1329-1335. doi:10.1038/

s..cdd. 4401309

Published online 8 August 2003

Keywords: EPM1; progressive myoclonus epilepsy; Unverricht-Lundborg; cystatin B; stefin B; Bid; cathepsin; apoptosis; cell death; ataxia; granule cell; cerebellum; lysosome

Abbreviations: EPM1, Unverricht-Lundborg progressive myoclonus epilepsy; TUNEL, terminal deoxynucleotidyl transferase dUTP nick-end labeling

\section{Introduction}

Apoptotic cell death initiated by extrinsic or intrinsic signaling mechanisms normally proceeds via a cascade of cleavage events mediated by cysteine proteases called caspases. In the extrinsic mode, membrane receptor signaling activates upstream initiator caspases, such as caspase-8. In some cells, activated caspase- 8 can then cleave the proapoptotic Bcl-2 family member Bid. Activated Bid causes the release of cytochrome $c$ from mitochondria and subsequent activation of downstream effector caspases, which carry out the final cleavage steps responsible for the cellular disassembly characteristic of apoptosis. ${ }^{1,2}$ In addition to the traditional apoptotic process mediated by caspases, other proteases such as the cathepsin cysteine proteases have been shown to participate in apoptotic signaling. ${ }^{3-14}$ Although cathepsins normally reside in the lysosome and carry out nonselective degradation of proteins, a strong case was made for the involvement of these proteases in apoptosis when it was shown that agents that disrupted lysosomes and caused cathepsins to redistribute to the cytoplasm inevitably resulted in apoptosis. ${ }^{13,15-19}$ Similarly, cathepsin inhibitor treatment blocked this apoptosis. ${ }^{11,14,18-22}$

Theoretically, the cathepsin proteases could induce apoptosis by a variety of different mechanisms. ${ }^{23}$ One possibility is that cathepsins could nonspecifically degrade important cellular proteins, thereby causing the cell to initiate apoptosis. ${ }^{24}$ Alternatively, cathepsins could cleave and activate caspases or their downstream death effector substrates, ${ }^{25}$ thereby causing apoptosis. In support of the former mechanism, it has been shown that cathepsin B can activate the inflammatory caspases 1 and $11,{ }^{17,26}$ and that cathepsin $\mathrm{L}$ may activate caspase- $3 .{ }^{20}$ The final possible mode of cathepsin action places cathepsins far upstream in the apoptotic cascade, cleaving the proapoptotic Bcl-2 family member Bid to initiate mitochondrial release of cytochrome $c$. This last hypothesis received in vitro confirmation when it was shown that lysosomal extracts containing cathepsins were able to cleave purified Bid in a physiologically relevant manner that supported apoptosis. ${ }^{27}$ Cytosolic extracts prepared from Bid-deficient mice resulted in significantly less apoptosis, demonstrating the dependence of this pathway on Bid. In support of this idea, a subsequent study showed that the selective disruption of lysosomes resulted in Bid activation and apoptosis; ${ }^{28}$ however, a very recent report using an in vitro endothelial cell system failed to show a requirement for Bid in cathepsin B-mediated apoptosis. ${ }^{14}$

We decided to test whether this intriguing Bid-mediated cathepsin-signaling mechanism occurs in vivo. The in vivo system we selected was a murine model of inherited epilepsy in which cathepsins contribute to the initiation or propagation of apoptosis when their endogenous cysteine protease inhibitor, cystatin B, is missing. ${ }^{29}$ These cystatin B-deficient mice experience widespread cerebellar granule cell apoptosis, ataxia, and seizures, just as do humans with UnverrichtLundborg progressive myoclonus epilepsy (EPM1) who lack cystatin $B .{ }^{30}$ With the endogenous inhibitor cystatin B missing, 
cathepsins are free to participate in activating the apoptotic pathway, and thereby contribute to the pathogenesis of EPM1 disease. To test whether cathepsins cause apoptosis by cleaving Bid, our strategy was to compare the amount of apoptosis and resultant phenotypes in these cystatin Bdeficient mice to the amount in cystatin B-deficient mice that were also made to lack Bid. We hypothesized that if cathepsins were signaling via Bid exclusively, the severity of apoptosis and other phenotypes would be diminished in the doubly deficient mice. Since the apoptosis, ataxia, and seizure phenotypes were not decreased in the cystatin $\mathrm{B}-/-$ Bid $-/-$ mice that we produced, we concluded that Bid is not required for cathepsin-mediated apoptotic signaling in this particular in vivo model of cell death.

\section{Methods}

\section{Mice}

Cystatin B-deficient mice and Bid-deficient mice were created as described previously. ${ }^{30-31}$ Mice heterozygous for cystatin $\mathrm{B}$ were bred to Bid heterozygous mice, to create progeny that were heterozygous for both deletions. These double heterozygotes were bred to each other to produce mice doubly deficient for both cystatin $B$ and Bid in addition to all the necessary controls (cystatin B $+/+\mathrm{Bid}+/+$, cystatin B - /Bid $+/+$, cystatin $\mathrm{B}+/+\mathrm{Bid}-/-)$. All mice were genotyped by PCR as previously described. ${ }^{30,31}$

\section{Western blots}

Cerebella from four wild-type and four cystatin B -/-, agematched, 4-month-old mice were homogenized in $10 \mathrm{mM}$ Tris$\mathrm{HCl}, \mathrm{pH} 7.2,142.5 \mathrm{mM} \mathrm{KCl}, 5 \mathrm{mM} \mathrm{MgCl}_{2}, 1 \mathrm{mM}$ EDTA, and $0.25 \%$ NP-40 with protease inhibitors. ${ }^{31}$ Equal amounts of protein were size fractionated by SDS-PAGE, transferred, and immunoblots were incubated with Cystatin B (Cat.\# 24098307, Biogenesis), Caspase-3 (Cat.\# 9662, Cell Signaling) or Bid (Cat.\# AF860, R\&D Systems) antibodies. Secondary HRP-conjugated antibodies were added and Western blots were developed using chemiluminescence detection (Amersham).

\section{Transferase-mediated dUTP nick-end labeling analysis}

Mice were transcardially perfused with $4 \%$ paraformaldehyde, and brains were postfixed overnight before being paraffin embedded and sectioned. The terminal deoxynucleotidyl transferase-mediated dUTP nick-end labeling (TUNEL) assay for apoptosis was performed according to the manufacturer's instructions for paraffin-embedded tissues (Cat.\# G3250, Promega). The number of fluorescently labeled apoptotic cells was quantitated using Zeiss KS 300 image analysis software. Bilateral samples of three low-magnification fields from each brain hemisphere were imaged for a total of six fields per mouse. The number of apoptotic cells was measured in 2month-old mice ( $n=4)$, 4-month-old mice $(n=9)$, and 8-monthold mice $(n=3-4)$ of each genotype. Unpaired, two-tailed
Student's $t$-test was used to evaluate the differences between genotypes.

\section{Ataxia measurements}

Mice, 2-month old ( $n=4)$, 4-month-old ( $n=9)$, and 8-month-old $(n=3-4)$, of each genotype were tested for ataxia by using a rotating-rod apparatus (Columbus Instruments) at both 0 and 2 rpm speeds. Mice were placed on the rod for a total of five consecutive trials of 1 min duration each. Mice remaining on the rod for $1 \mathrm{~min}$ received a perfect score. Unpaired, two-tailed Student's $t$-test was used to evaluate the differences between genotypes.

A second ataxia measurement, the gait variability paradigm, ${ }^{32,33}$ was also used to test 2 -month-old mice $(n=4)$, 4-month-old mice $(n=9)$, and 8-month-old mice $(n=3-4)$ of each genotype. After dipping the hind paws of mice in ink, the mice were allowed to run from the entrance end of an enclosed $60 \mathrm{~cm}$ long runway lined with paper to the exit end. The variability of spacing between footsteps as marked by the ink is an index of ataxia. The mean log variance of the distance between hind paws for at least 10 successive steps was calculated for each mouse, and averaged for each of the two testing repetitions. An average mean log variance of greater than one was taken as an indication of ataxia.

\section{Cortical EEG and seizure measurements}

Doubly deficient cystatin B $-/-$ Bid $-/-$ mice and singly deficient cystatin B -/- mice were observed at different ages for evidence of seizures. For electrocorticographic recordings, silver-wire electrodes $\left(0.005^{\prime \prime}\right.$ diameter) soldered to a microminiature connector were implanted bilaterally into the subdural space over the frontal and parietal cortex of anesthetized mice, several days prior to recording. Cortical activity and behavior were recorded using a digital video/ electroencephalograph (Stellate Systems) from 8-9-monthold mutants and controls moving freely in the test cage for prolonged periods $(>2 \mathrm{~h}$ ) during a minimum of five sessions, including overnight recordings.

\section{Results}

\section{No Bid cleavage in cystatin B-deficient cerebella}

It had been previously shown that cathepsin $B$ is responsible for a significant percentage of the cerebellar granule cell apoptosis that results when its inhibitor cystatin $B$ is absent in mice. $^{29}$ For this reason, we used the cystatin B-deficient mouse system to determine if in vivo proapoptotic signaling by cathepsins requires the presence of Bid to initiate or propagate apoptosis. Our initial test of this proposed mechanism was to compare amounts of Bid cleavage in wild-type and cystatin B-deficient cerebella. We first confirmed the presence of cystatin B protein in wild-type but not cystatin B knockout cerebellar protein homogenates by Western blotting (Figure 1). Next, we established that the cerebellar cell death that we had previously observed was indeed apoptotic, by blotting for the cleaved form of caspase3. Lastly, we looked for the evidence of Bid cleavage in cystatin B $+/+$ and cystatin B -/- cerebellar homogenates. 


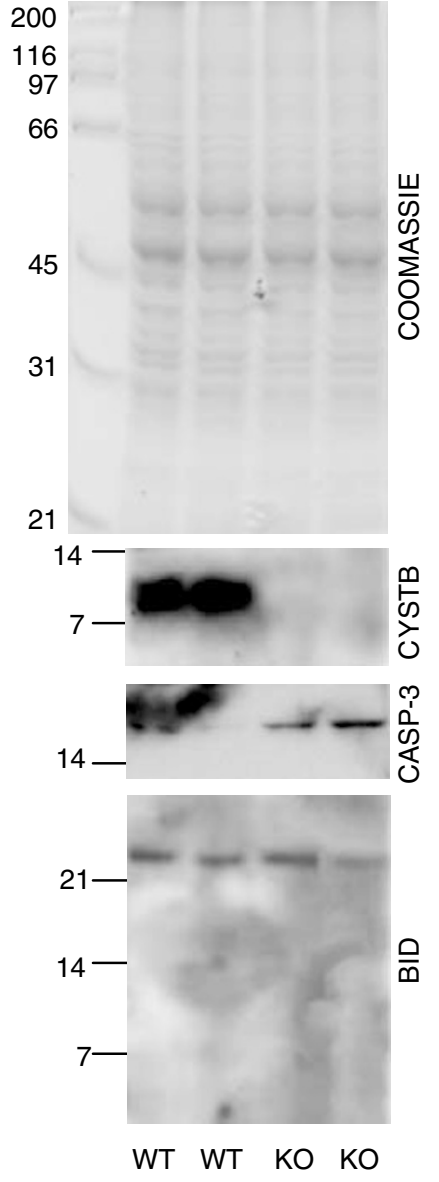

Figure 1 Lack of Bid cleavage in wild-type and cystatin B-deficient mouse cerebella. Cerebellar total homogenates from 4-month-old wild-type (WT) and cystatin B-deficient (KO) mice were resolved on SDS-PAGE gels. Equal loading of protein samples is shown by Coomassie blue staining in the top panel. Western blotting for cystatin B demonstrates that WT cerebella contain cystatin $B$ protein, whereas cystatin B KO cerebella do not. A duplicate membrane blotted for caspase-3 shows evidence for apoptosis in the cystatin B -1 - cerebella: increased accumulation of the capase-3 active $17 \mathrm{kDa}$ fragment in cystatin B KO cerebella as compared with WT cerebella. Another duplicate membrane blotted for Bid shows the existence of the uncleaved $22 \mathrm{kDa}$ form of Bid, but no $15 \mathrm{kDa}$ active form in WT or cystatin B-deficient cerebella

The inactive form of Bid is approximately $22 \mathrm{kDa}$, but upon cleavage and activation, Bid is reduced to a $15 \mathrm{kDa}$ piece. If Bid is a major contributor to cathepsin-mediated apoptotic signaling, we would expect to see the accumulation of the $15 \mathrm{kDa}$ form of Bid in cystatin B $-/$ - cerebella, and not in cystatin B $+/+$ mice where no apoptosis is observed. Instead, we detected no Bid cleavage products nor any disappearance of the full-length Bid with any of the anti-Bid antisera that we tested (Figure 1), arguing against the involvement of Bid in this system.

\section{Production of cystatin B, Bid doubly deficient mice}

To determine whether cathepsin-mediated apoptosis is possible in the absence of Bid, we constructed cystatin $\mathrm{B} / \mathrm{Bid}$ double knockout mice. Removing Bid, the potential signaling intermediate between cathepsins and caspases, should decrease or abolish the phenotypes of cystatin
B-deficient mice if Bid is a critical component of cathepsinmediated apoptosis. The double mutants were generated in two rounds of breeding, such that $1 / 16$ of the progeny were doubly deficient for cystatin B and Bid. Cystatin B -/- Bid -/mice were phenotypically normal at birth, and were born at the expected Mendelian ratio.

\section{Granule cell apoptosis is unchanged in cystatin B, Bid doubly deficient mice}

To assess whether removal of Bid from cystatin B-deficient mice reduced the severity of the apoptosis phenotype, we visualized the amount of cerebellar granule cell apoptosis in brains from doubly deficient mouse lines at 2, 4, and 8 months of age. As expected, there was little to no visible cerebellar granule cell apoptosis in cystatin B $+/+$ Bid $+/+$ wild-type mice at 2 months (Figure 2a), 4 months (Figure 2d), or 8 months of age (Figure $2 \mathrm{~g}$ ). Cystatin $\mathrm{B}-/-\mathrm{Bid}+/+$ disease mice displayed widespread granule cell apoptosis at 2 months (Figure 2b), 4 months (Figure 2e), and 8 months of age (Figure $2 \mathrm{~h}$ ), as previously reported. Cystatin B -/- Bid -Idisease mice displayed equivalent granule cell apoptosis at 2 months (Figure 2c), 4 months (Figure 2f), and 8 months of age (Figure 2i).

We quantitated the number of TUNEL-positive granule cells for each of the genotypes at 2, 4, and 8 months of age (Figure 2j). At 2 months of age, cystatin B $-/-$ Bid $+/+$ disease mice had an average of 96 apoptotic granule cells per field, whereas doubly deleted cystatin B $-/-$ Bid $-/$ - mice had an average of 81 apoptotic granule cells per field. This $16 \%$ difference was not statistically significant $(P=0.412)$. At 4 months of age, the doubly deleted mice displayed a similar small reduction in the number of apoptotic granule cells when compared to cystatin B-deficient mice, but again this difference was not statistically significant $(P=0.228)$. Cystatin $\mathrm{B}-/-\mathrm{Bid}+/+$ mice (8-month old) and cystatin B - /- Bid -/ - mice experienced nearly equivalent amounts of granule cell apoptosis, with an average of 39 and 40 TUNEL-positive cells per field, respectively $(P=0.963)$. Since the removal of Bid from the cystatin B-deficient disease mice did not abolish granule cell apoptosis, we conclude that Bid signaling alone is dispensable for the cathepsin-mediated form of apoptosis observed in this disease.

\section{Ataxia is unchanged in cystatin B, Bid doubly deficient mice}

Previously, we showed that aged cystatin B-deficient mice experience ataxia, consisting of poor balance while moving, and a lack of motor coordination. ${ }^{30}$ To determine whether Bid signaling contributes to this phenotype in the absence of cystatin $B$, we tested the cystatin $B$, Bid doubly deficient mice described above for reduced ataxia. Wild-type cystatin $\mathrm{B}+I+\mathrm{Bid}+I+$ mice performed well on the rotorod ataxia test at all ages, remaining on the $0 \mathrm{rpm}$ rod (Figure $3 \mathrm{a}$ ) or $2 \mathrm{rpm}$ rod (Figure $3 \mathrm{~b}$ ) for each full $60 \mathrm{~s}$ trial. Cystatin B $-/-$ Bid $+I+$ disease mice performed well at 2 and 4 months of age, but by 8 months of age experienced ataxia, as evidenced by a greatly decreased ability to stay on either the stationary or 

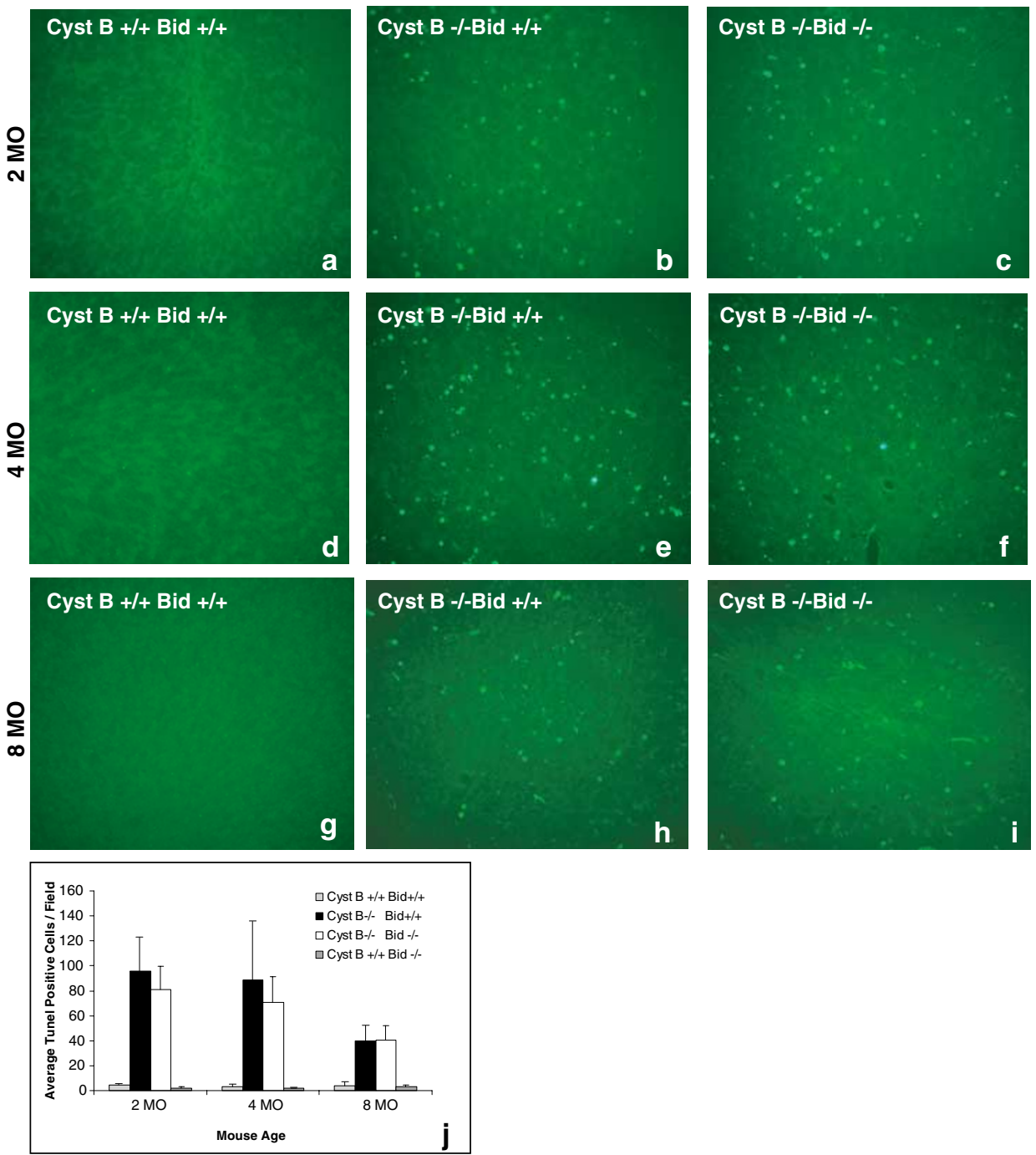

Figure 2 Granule cell apoptosis in cystatin B, Bid doubly deficient mice. TUNEL staining of cerebellar sections from 2-month-old mice (a-c), 4-month-old mice (d-f), or 8-month-old mice (g-i) to visualize apoptosis. At 2 months of age, there was (a) no apoptosis in cystatin B $+I+$ Bid $+I+$ wild-type mice, whereas (b) cystatin B - $/-$ $\mathrm{Bid}+I+$ mice and (c) doubly deficient cystatin B $-I-$ Bid $-I-$ mice experienced equivalent amounts of apoptotic granule cells. At 4 months of age, there was (d) no apoptosis in cystatin B $+I+$ Bid $+/$ + wild-type mice, whereas (e) cystatin B - / - Bid $+/+$ mice and (f) doubly deficient cystatin B - I- Bid - I- mice experienced equivalent amounts of apoptotic granule cells. At 8 months of age, there was $(\mathbf{g})$ no apoptosis in cystatin B $+I+$ Bid $+I+$ wild-type mice, whereas (h) cystatin B - IBid $+I+$ mice and (i) doubly deficient cystatin B $-I-$ Bid $-/$ - mice experienced equivalent amounts of apoptotic granule cells. Quantitation of apoptotic granule cells at 2,4 , and 8 months of age confirmed that (j) cystatin B $-I-$ Bid $+I+$ mice experienced similar amounts of cell death as cystatin B $-I-B$ id $-I-$ mice at all ages tested. Cystatin B $+I+$ Bid $+I+$ and Cystatin B $+I+$ Bid $-I-$ mice did not experience appreciable granule cell apoptosis. Error bars=standard deviation. Scale bar $=200 \mu \mathrm{m}(\mathrm{a}-\mathrm{i})$

rotating rod during the trial. The doubly deficient cystatin B -I- Bid -/- mice had nearly normal capability at 2 and 4 months of age, but by 8 months of age were compromised to a similar degree as were the cystatin $\mathrm{B}-/-\mathrm{Bid}+/+$ mice. Although cystatin $\mathrm{B}-/-\mathrm{Bid}-/-$ mice showed a slight trend towards better rotorod performance than the cystatin B -/Bid $+I+$ mice, individual doubly deleted mice had variable performances, and the difference between genotypes did not reach statistical significance at either 0 or $2 \mathrm{rpm}(P=0.051$ and 0.092 , respectively). Similar findings were obtained with the gait variability test to measure ataxia in these mice (Figure 3c). Specifically, cystatin B - /- Bid + / + mice and cystatin B -/Bid -/- mice displayed ataxic symptoms only at 8 months of age, and the removal of Bid from cystatin B-deficient mice did not reduce the severity of ataxia. Thus, Bid signaling does not appear to be an important pathway responsible for the ataxia phenotype in cystatin B-deficient mice or humans.

\section{Seizures measured in cystatin B, Bid doubly deficient mice}

During sleep, cystatin B - /- mice experience frequent seizures that consist of ear, vibrissae, head, tail, and wholebody myoclonus. Electroencephalograph recordings (EEG) from these mice show stereotypical synchronous spikes consistent with myoclonic seizures. ${ }^{30}$ To determine whether the removal of Bid from cystatin $B-/-$ mice abolished the cystatin B - /- seizure phenotype, we first made visual observations of double knockout mice. Multiple doubly deficient mice had seizures upon falling asleep. To better 
a

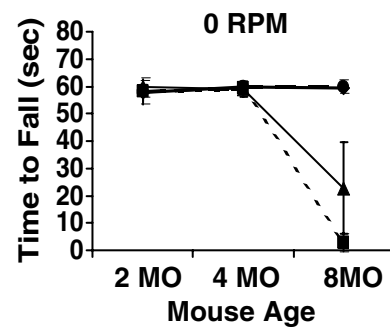

C

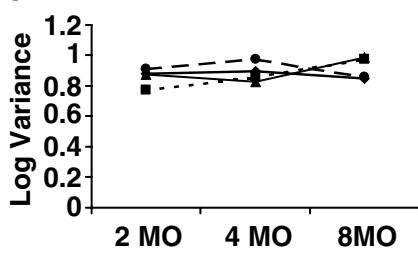

b

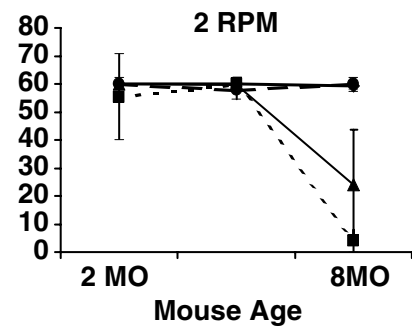

$\rightarrow$ Cyst B +/+ Bid +/+

- Cyst B-l- Bid $+/+$

I- Cyst B-/- Bid -/-

$\rightarrow$ - Cyst B +/+ Bid -/-

Figure 3 Ataxia measurements in cystatin B, Bid doubly deficient mice. The still (a) and rotating (b) rotorods were used to measure ataxia at 2, 4, and 8 months of age. The gait variability paradigm (c) was used to measure ataxia at 2,4 , and 8 months of age. Cystatin B $+I+$ Bid $+I+$ mice (heavy line, diamonds) and cystatin $B+I+$ Bid $-/-$ mice (dashed line, circles) showed no signs of ataxia at any age on the (a) still or (b) rotating rod. Cystatin B $-I-$ Bid $+I+$ mice (dashed line, squares) showed a greatly reduced ability to remain on the (a) still or (b) rotating rod by 8 months of age, as did cystatin B $-/-$ Bid $-/-$ mice (light line, triangles). (c) Cystatin B $-I-$ Bid $+I+$ mice (dashed line, squares) and cystatin $\mathrm{B}-/-$ Bid $-/$ - mice (light line, triangles) both experienced more gait variability than cystatin $\mathrm{B}+I+\mathrm{Bid}+I+$ mice (heavy line, diamonds) and cystatin B $+I+$ Bid $-I-$ mice (dashed line, circles) at 8 months of age. Error bars $=$ standard deviation

characterize the seizure type and severity, EEG recordings were performed on doubly deficient mice, and compared to recordings from singly deficient cystatin $\mathrm{B}-/-$ disease mice. Cystatin B -/- Bid -/- (Figure 4a) and cystatin B -/Bid $+/+$ mice (Figure $4 b$ ) displayed frequent spontaneous axial myoclonic jerks associated with a bilateral $150-300 \mathrm{~ms}$ electrographic discharge, typically at the rate of $10-15 \mathrm{~h}$. These solitary myoclonias always involved the head and neck, and usually the entire body. Myoclonus occurred both during wakefulness and sleep, and often the discharge was sufficient to awaken the animal. The baseline cortical activity of both doubly (Figure 4c) and singly (Figure 4d) deficient mice showed periods of normal, low-amplitude desynchronized EEG, and, at times, interictal discharges not associated with myoclonic jerks were present, as were bilateral electrographic seizure discharges. During these seizures, which could be observed both during sleep and wakeful behavior, the mouse showed no clonic or tonic movements, and was able to explore and engage in feeding behavior. Since the removal of Bid from cystatin B -/- mice did not measurably alter the seizure or myoclonia phenotypes, we conclude that Bid is not required for the manifestation of these neuronal excitability phenotypes.

\section{Eye phenotype present in cystatin B, Bid doubly deficient mice}

In our original characterization of the singly deficient cystatin B $-1-$ mice, we noted that approximately $35 \%$ of these mice
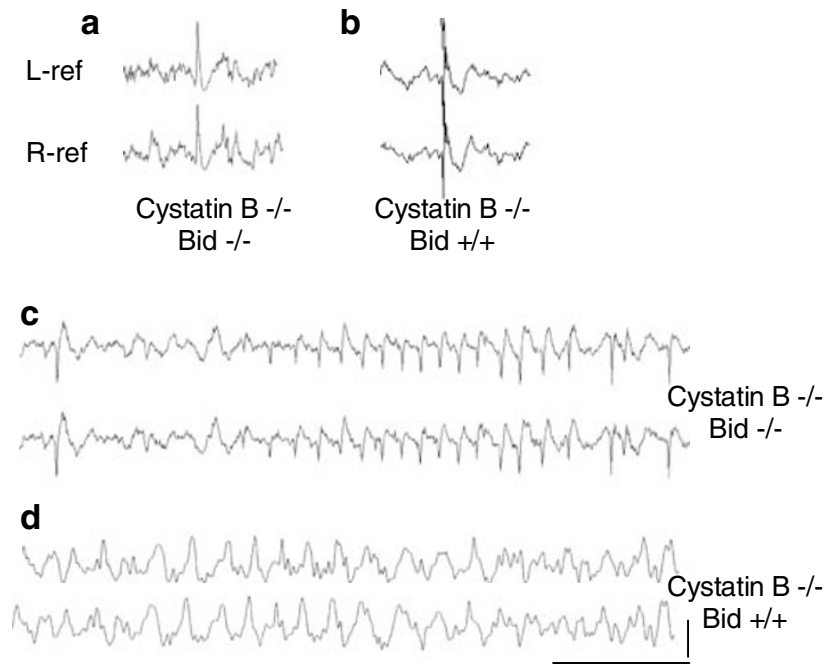

Figure 4 Electrocorticographic activity recordings from cystatin B, Bid doubly deficient mice show myoclonus and seizures. Representative examples of spontaneous bilateral cortical discharges associated with myoclonic jerks from (a) a cystatin B $-I-$ Bid $-I-$ mouse and (b) a cystatin B $-/-$ Bid $+/+$ mouse. Electrocorticographic monitoring of (c) cystatin B $-/-$ Bid $-/-$ mutant mice and (d) cystatin B $-I-$ Bid $+I+$ mutant mice reveals spontaneous bilaterally synchronous interictal discharges during waking behavior, with a rapid progression to continuous spike and spike-wave rhythmic seizure activity, and termination of the seizure. Calibration bars: (a, b) $0.2 \mathrm{mv}, 1 \mathrm{~s}$; (c) $0.5 \mathrm{mv}, 1 \mathrm{~s}$; (d) $0.2 \mathrm{mv}, 0.5 \mathrm{~s}$

Table 1 Eye phenotype prevalence in 8-month-old cystatin B, cathepsin doubly deficient mice

\begin{tabular}{lc}
\hline Mouse genotype & $\begin{array}{c}\text { Number of mice with } \\
\text { phenotype/total }\end{array}$ \\
\hline Cystatin B -/- Bid +/+ & $2 / 4(50 \%)$ \\
Cystatin B -/- Bid -/- & $2 / 3(66 \%)$ \\
\hline
\end{tabular}

experienced a mild eye phenotype consisting of corneal lesions and or serous exudate in one or both eyes. ${ }^{30}$ To determine whether the removal of Bid influenced the severity of these eye lesions, we counted the number of 8-month-old doubly deficient mice with this eye phenotype. We found that half of the cystatin $\mathrm{B}-/-\mathrm{Bid}+/+$ mice experienced the eye phenotype, whereas two-thirds of the cystatin B -/- Bid -/mice did (Table 1). While the small number of 8 -month-old animals available for this measurement precludes any firm conclusions, the fact that there was no decrease in the incidence of the eye phenotype upon Bid removal indicates that Bid was not required for the emergence of this phenotype.

\section{Discussion}

We tested whether the proapoptotic signaling by lysosomal cathepsin proteases proceeds via the proapoptotic Bcl-2 family member Bid in vivo. To do this, we used a murine model of human epilepsy in which cathepsins are not inhibited due to a systemic lack of their endogenous inhibitor, cystatin B. We found no evidence for Bid cleavage/activation in cystatin 
B-deficient mouse cerebella undergoing apoptosis. We also compared the severity of apoptosis and other phenotypes in these cystatin B-deficient mice to that of cystatin B-deficient mice engineered to also lack Bid. We showed that the amount of cerebellar granule cell apoptosis in cystatin B-deficient mice did not change when Bid was removed. Similarly, these cystatin B -/-Bid -/- mice experienced ataxia, seizure, and eye phenotypes equivalent to those observed in singly deficient cystatin B $-/-$ mice. These findings indicate that cathepsins can use mechanisms other than Bid cleavage to initiate or propagate apoptosis in this system. Alternatively, another molecule may partially substitute for Bid when it is missing. This simple explanation seems plausible, as the original in vitro experiments on which the current study is based also provided evidence for the existence of another compensatory factor by showing reduced, but not abolished, ability of Bid-deficient extracts to promote apoptosis. ${ }^{27}$

If cathepsins do not signal apoptosis exclusively via Bid, then what other molecule is downstream for the cathepsins to cleave? The likely candidates are other Bcl-2 family members that could compensate for the proapoptotic function of Bid when Bid is removed. One possibility is that cathepsins cleave the antiapoptotic Bcl-2 family members, thereby destroying their antiapoptotic function. For example, the Bcl-2 family members $\mathrm{Bcl}-2$ and $\mathrm{Bcl}-\mathrm{X}_{\mathrm{L}}$ can be cleaved to convert them from their normal antiapoptotic state to a proapoptotic state. ${ }^{34,35}$ Alternatively, cathepsins could simply degrade the antiapoptotic Bcl-2 family members with similar consequences. It is also possible that cathepsins mediate apoptosis through cleavage of some of the other proapoptotic members of the Bcl-2 family (Bax, Bak, Bok, Bim, Bik, Bad, Hrk, and Noxa) that normally act to sense cellular damage and initiate apoptosis. Although many of these do not appear to require proteolysis for activation, ${ }^{36}$ it cannot be excluded that one or two of the family members require cleavage to become active, as is the case for Bid.

Given the compelling in vitro data showing that Bid is the predominant signaling intermediate between lysosomal proteases and apoptosis induction, ${ }^{27,28}$ our current in vivo results were unexpected, and prompted us to consider other interpretations of the original data from Stoka and colleagues. For example, because their in vitro study used total lysosomal extracts instead of purified individual lysosomal cathepsins for the Bid cleavage assays, it seems possible that other unidentified lysosomal components besides cathepsins could have been responsible for the cleavage and activation of Bid. Namely, there are more than 50 hydrolytic enzymes present in lysosomes, ${ }^{37}$ and some are already implicated in apoptosis. ${ }^{38,39}$ To help resolve whether cathepsins are in fact the lysosomal components that cause Bid cleavage in vitro, additional follow-up studies aimed at identifying which cathepsins can cleave Bid are currently underway. Preliminary evidence shows that cathepsins $B, L, H, S$, and $K$ can mediate this cleavage event, whereas cathepsins $X$ and $C$ cannot (Boris Turk, unpublished data). If this holds true, other reasons may explain why our in vivo system did not replicate these in vitro results. One likely explanation is that, while cathepsins are physically capable of cleaving Bid in vitro, this phenomenon may not occur in in vivo settings due to inefficient cleavage or insufficient quantities of cytoplasmic cathepsins. Alternatively, it is possible that cathepsinmediated Bid cleavage occurs only in certain cell types, and that a cofactor or particular condition must be present for Bid cleavage to occur. This is in agreement with the finding that apoptosis induced by lysosomal disruption in HeLa cells proceeds through cathepsin-mediated Bid cleavage (Boris Turk, unpublished) and cathepsin-mediated Bid cleavage occurs readily in extracts made from liver cells, ${ }^{27}$ but Bid is not required for cathepsin-mediated apoptosis in our granule cell system. In support of this idea, it is well known that Bid is required in only a subset of cell types and in cell death caused by a certain subset of stimuli. ${ }^{40}$ The fact that apoptotic cell death in Bid-deficient mice occurs relatively normally and Biddeficient mice do not have the same severe phenotypes as do knockouts of other members of the extrinsic signaling pathway (such as caspase $8,{ }^{41}$ Fadd, ${ }^{42,43}$ or Fas-deficient mice ${ }^{44}$ ) also argues for the existence of a compensatory mechanism or molecule in addition to Bid.

We believe that the apoptotic signals initiated or propagated by cathepsins represent subtle but important aspects of the apoptotic response. For example, the cell may use cathepsins to sense moderate lysosomal damage or oxidative stress. Alternatively, cathepsins may represent a backup apoptotic mechanism or a way to amplify weak apoptotic signals when caspases are inhibited. It is important to elucidate the mechanism of this cathepsin-mediated apoptosis so that we can start to determine how universal this process is and for which cell types it is crucial. Besides showing that cathepsins may utilize Bid signaling to different extents in in vivo versus in vitro settings, we have demonstrated that cathepsins no longer held in check by their inhibitor cystatin B find ways other than Bid activation to induce apoptosis in humans and mice with EPM1. We expect that future studies aimed at identifying the downstream targets of cathepsin proteolysis will contribute greatly to the understanding of EPM1 pathogenesis, and may reconcile the long-standing questions surrounding lysosomal cathepsin involvement in apoptosis.

\section{Acknowledgements}

We are grateful to Loan Nguyen for assistance with mouse genotyping. We thank Dr. Ravi Tolwani for use of the rotor rod apparatus. MKH was supported by an Epilepsy Foundation postdoctoral fellowship through the generous support of the American Epilepsy Society and the Milken Family Foundation. AV and JLN were supported by NINDS grant NS29709. X-MY was supported by grant CA 83817 .

\section{References}

1. Luo X, Budihardjo I, Zou H, Slaughter C and Wang X (1998) Bid, a Bcl-2 interacting protein, mediates cytochrome $c$ release from mitochondria in response to activation of cell surface death receptors. Cell 94: 481-490

2. Li H, Zhu H, Xu CJ and Yuan J (1998) Cleavage of BID by caspase-8 mediates the mitochondrial damage in the Fas pathway of apoptosis. Cell 94: 481-501

3. Nitatori T, Sato N, Kominami E and Uchiyama Y (1996) Participation of cathepsins $B, H$, and $L$ in perikaryal condensation of $C A 1$ pyramidal neurons undergoing apoptosis after brief ischemia. In Intracellular Protein Catabolism Suzuki and Bond (eds) (New York: Plenum Press), 177-185 
4. Monney L, Olivier R, Otter I, Jansen B, Poirier GG and Borner C (1998) Role of an acidic compartment in tumor-necrosis-factor- $\alpha$ production of ceramide, activation of caspase-3 and apoptosis. Eur. J. Biochem. 251: 295-303

5. Guicciardi ME, Deussing J, Miyoshi H, Bronk SF, Svingen PA, Peters C, Kaufmann SH and Gores GJ (2000) Cathepsin B contributes to TNF- $\alpha$ mediated hepatocyte apoptosis by promoting mitochondrial release of cytochrome c. J. Clin. Invest. 106: 1127-1137

6. Foghsgaard L, Wissing D, Mauch D, Lademann U, Bastholm L, Boes M, Elling $F$, Leist $M$ and Jäättelä $M(2001)$ Cathepsin $B$ acts as a dominant execution protease in tumor cell apoptosis induced by tumor necrosis factor. J. Cell Biol. 153: 999-1009

7. Guicciardi ME, Miyoshi H, Bronk SF and Gores GJ (2001) Cathepsin B knockout mice are resistant to tumor necrosis factor-alpha-mediated hepatocyte apoptosis and liver injury: implications for therapeutic applications. Am. J. Pathol. 159: 2045-2054

8. Kingham PJ and Pocock JM (2001) Microglial secreted cathepsin B induces neuronal apoptosis. J. Neurochem. 76: 1475-1484

9. Mathiasen IS, Hansen CM, Foghsgaard L and Jäättelä M (2001) Sensitization to TNF-induced apoptosis by 1,25 -dihydroxy vitamin $\mathrm{D}_{3}$ involves up-regulation of the TNF receptor 1 and cathepsin B. Int. J. Cancer 93: 224-231

10. Foghsgaard L, Lademann U, Wissing D, Poulsen B and Jäättelä M (2002) Cathepsin $\mathrm{B}$ mediates tumor necrosis factor-induced arachidonic acid release in tumor cells. J. Biol. Chem. 277: 39499-39506

11. Fujimoto K, Yamamoto T, Kitano T and Abe S-I (2002) Promotion of cathepsin $L$ activity in newt spermatagonial apoptosis induced by prolactin. FEBS Lett. 521: $43-46$

12. Werneburg NW, Guicciardi ME, Bronk SF and Gores GJ (2002) Tumor necrosis factor- $\alpha$-associated lysosomal permeabilization is cathepsin B dependent. Am. J. Physiol. Gastrointest. Liver Physiol. 283: G947-G956

13. Yuan XM, Li W, Dalen H, Lotem J, Kama R, Sachs L and Brunk UT (2002) Lysosomal destabilization in p53-induced apoptosis. Proc. Natt. Acad. Sci. USA 99: 6286-6291

14. Madge L, Li J-H, Choi J and Pober JS (2003) Inhibition of PI-3 kinase sensitizes vascular endothelial cells to cytokine-initiated cathepsin-dependent apoptosis. J. Biol. Chem. 278: 21295-21306

15. Yuan XM, Li W, Olsson AG and Brunk UT (1997) The toxicity to macrophages of oxidized low-density lipoprotein is mediated though lysosomal damage. Atherosclerosis 133: 153-161

16. Ishisaka R, Utsumi T, Yabuki M, Kanno T, Inoue M and Utsumi K (1998) Activation of caspase-3 like protease by digitonin-treated lysosomes. FEBS Lett. 433: 233-236

17. Vancompernolle K, Van Herreweghe F, Pynaert G, Van de Craen M, De Vod K, Trotty N, Sterling A, Fiers W, Vandenebeele P and Grooten J (1998) Atractyloside-induced release of cathepsin $\mathrm{B}$, a protease with caspaseprocessing activity. FEBS Lett. 438: 150-158

18. Ishisaka R, Kanno T, Akiyama J, Yoshioka T, Utsumi K and Utsumi T (2001) Activation of caspase-3 by lysosomal cysteine proteases and its role in 2,2'azobis-(2-amidino propane) dihydrochloride (AAPH)- induced apoptosis in $\mathrm{HL}$ 60 cells. J. Biochem. 129: 35-41

19. Kågedål $K$, Zhao $M$, Svensson I and Brunk UT (2001) Sphingosine-induced apoptosis is dependent on lysosomal proteases. Biochem. J. 359: 335-343

20. Ishisaka R, Utsumi T, Kanno T, Arita K, Katunuma N, Akiyama J and Utsumi K (1999) Participation of a cathepsin L-type protease in the activation of caspase3. Cell Struct. \& Funct. 24: $465-470$

21. Gray J, Haran MM, Schneider K, Vesce S, Ray AM, Owen D, White IR, Cutler P and Davis JB (2001) Evidence that inhibition of cathepsin-B contributes to the neuroprotective properties of caspase inhibitor tyr-val-ala-asp-chloromethyl ketone. J. Biol. Chem. 276: 32750-32755

22. Hishita T, Tada-Oikawa S, Tohyama K, Miura Y, Nishihara T, Tohyama $Y$, Yoshida Y, Uchiyama T and Kawanishi S (2001) Caspase-3 activation by lysosomal enzymes in cytochrome $c$-independent apoptosis in myelodysplastic syndrome-derived cell line P39. Cancer Res. 61: 2878-2884

23. Turk B, Stoka V, Rozman-Pungercar J, Cirman T, Droga-Mazovec G, Oresic K and Turk $V$ (2002) Apoptotic pathways: involvement of lysosomal proteases. Biol. Chem. 383: 1035-1044

24. Williams MS and Henkart PA (1994) Apoptotic cell death induced by intracellular proteolysis. J. Immunol. 153: 4247-4255
25. Gobeil S, Boucher CC, Nadeau D and Poirier GG (2001) Characterization of the necrotic cleavage of poly(ADP-ribose) polymerase (PARP-1): implication of lysosomal proteases. Cell Death and Differ. 8: 588-594

26. Schotte P, Criekinge WV, Van de Craen M, Van Loo G, Desmedt M, Grooten J, Cornelissen M, De Ridder L, Vandekerckhove J, Fiers W, Vandenabeele P and Beyaert R (1998) Cathepsin B-mediated activation of the proinflammatory caspase-11. Biochem. \& Biophys. Res. Comm. 251: 379-387

27. Stoka V, Turk B, Schendel SL, Kim TH, Cirman T, Snipas SJ, Ellerby LM, Bredesen D, Freeze H, Abrahamson M, Bromme D, Krajewski S, Reed JC, Yin X-M, Turk V and Salvesen GS (2001) Lysosomal protease pathways to apoptosis: cleavage of Bid, not pro-caspases, is the most likely route. J. Biol. Chem. 276: 3149-3157

28. Reiners JJ, Caruso JA, Mathieu P, Chelladurai B, Yin X-M and Kessel D (2002) Release of cytochrome $c$ and activation of pro-caspase-9 following lysosomal photodamage involves Bid cleavage. Cell Death Differ. 9: 934-944

29. Houseweart MK, Pennacchio LA, Villaythong A, Noebels JL, Peters $C$ and Myers RM (2003) Cathepsin B but not Cathepsins $L$ or $S$ contributes to the pathogenesis of Unverricht-Lundborg progressive myoclonus epilepsy (EPM1). J. Neurobiology (In Press)

30. Pennacchio LA, Bouley DM, Higgins KM, Scott MP, Noebels JL and Myers RM (1998) Progressive ataxia, myoclonic epilepsy and cerebellar apoptosis in cystatin B-deficient mice. Nat. Genet. 20: 251-258

31. Yin X-M, Wang K, Gross A, Zhao Y, Zinkel S, Klocke B, Roth KA and Korsmeyer SJ (1999) Bid-deficient mice are resistant to Fas-induced hepatocellular apoptosis. Nature 400: 886-891

32. Rushton $\mathrm{R}$ and Steinberg $\mathrm{H}$ (1963) Mutual potentiation of amphetamine and amylobarbitone measured by activity in rats. Br. J. Pharmacol. 21: 295-305

33. Chakrabarti A, Ekuta JE and Onaivi ES (1998) Neurobehavioral effects of cannabinoid receptor gene expression in mice. Br. Res. Bull 45: 67-74

34. Gil-Parrado S, Fernandez-Montalvan A, Assfalg-Machleidt I, Popp O, Bestvater F, Holloschi A, Knoch TA, Auerswald EA, Welsh K, Reed JC, Fritz H, FuentesPrior P, Spiess E, Salvesen GS and Machleidt W (2002) lonomycin-activated calpain triggers apoptosis. A probable role for Bcl-2 family members. J. Biol. Chem. 277: 27217-27226

35. Clem RJ, Cheng EH-Y, Karp CL, Kirsch DG, Ueno K, Takahashi A, Kastan MB, Griffin DE, Earnshaw WC, Veliuona MA and Hardwick JM (1998) Modulation of cell death by Bcl- $X_{L}$ though caspase interaction. Proc. Natl. Acad. Sci. 95: 554559

36. Adams JM and Cory S (2001) Life or death decisions by the Bcl-2 protein family. Tr. Bioschem. Sci. 26: 61-66

37. Pillay CS, Elliott E and Dennison C (2002) Endolysosomal proteolysis and its regulation. Biochem. J. 363: 417-429

38. Suter M, Reme C, Grimm C, Wenzel A, Jaattela M, Esser P, Kociok N, Leist M and Richter C (2000) Age related macular degeneration: the lipofuscin component $\mathrm{N}$-retinyl-Nretinylidene ethanolamine detaches proapoptotic proteins from mitochondria and induces apoptosis in mammalian retinal pigment epithelial cells. J. Biol. Chem. 275: 39625-39630

39. Katunuma N, Matsui A, Le QT, Utsumi K, Salvesen G and Ohashi A (2001) Novel procaspase-3 activating cascade mediated by lysoapoptases and its biological significances in apoptosis. Advan. Enzyme Regul. 41: 237-250

40. Ranger AM, Malynn BA and Korsmeyer SJ (2001) Mouse models of cell death. Nat. Genet. 28: 113-118

41. Varfolomeev EE, Schuchmann M, Luria V, Chiannilkulchai N, Beckmann JS, Mett IL, Rebrikov D, Brodianski VM, Kemper OC, Kollet O, Lapidot T, Soffer D, Sobe T, Avraham KB, Goncharov T, Holtmann H, Lonai P and Wallach D (1998) Targeted disruption of the mouse caspase 8 gene ablates cell death induction by the TNF receptors, Fas/Apo1, and DR3 and is lethal prenatally. Immunity 9: 267-276

42. Yeh WC, Pompa JL, McCurrach ME, Shu HB, Elia AJ, Shahinian A, Ng M, Wakeham A, Khoo W, Mitchell K, El-Deiry WS, Lowe SW, Goeddel DV and Mak TW (1998) FADD: essential for embryo development and signaling from some, but not all, inducers of apoptosis. Science 279: 1954-1958

43. Zhang J, Cado D, Chen A, Kabra NH and Winoto A (1998) Fas-mediated apoptosis and activation-induced T-cell proliferation are defective in mice lacking FADD/Mort1. Nature 392: 296-300

44. Watanabe-Fukunaga $\mathrm{R}$, Brannan $\mathrm{Cl}$, Copeland NG, Jenkins NA and Nagata S (1992) Lymphoproliferation disorder in mice explained by defects in Fas antigen that mediates apoptosis. Nature 356: 314-317 